\title{
Optimization of long-term Han River basin hydropower scheduling using linear programming
}

\author{
J. Ji ${ }^{1}$, E. Lee ${ }^{1}$, M. Yu ${ }^{1}$, J. Ahn ${ }^{1} \&$ J. Yi ${ }^{2}$ \\ ${ }^{1}$ Department of Civil and Transportation Engineering, \\ Ajou University, South Korea \\ ${ }^{2}$ Department of Civil Engineering, Ajou University, South Korea
}

\begin{abstract}
Power production in Korea can be classified into nuclear, thermal, and hydropower generation. The nuclear power plant occupies the largest portion of power generation, whilst hydropower only accounts for $2 \%$. Nevertheless, many people are interested in hydropower generation, because its power generation time is shorter than that of nuclear and thermal power. In addition, it is considered as clean energy. There are a large number of reservoirs and industries in the Han River basin. So, optimization of the power generation is necessary for the industry. In this study, the five hydroelectric reservoirs and the three multipurpose reservoirs which are placed in the Han River basin, are selected and examined to maximize power generation by monthly operation. The linear programming is used for 10 years historical data. The releases from the upper reservoir calculated from the optimization are utilized as inflows in the downstream reservoirs. The optimization results were compared with the historical data.
\end{abstract}

Keywords: hydropower generation, linear programming, reservoir operation.

\section{Introduction}

According to the $5^{\text {th }}$ report by the IPCC [1], the warming of the climate system is now unequivocal. Numerous changes observed since 1950 are unprecedented in the past thousands of years. Following the increasing uncertainty about water resources due to climate change, efficient usage of water resources has also become more important. In Korea, the proportion that hydroelectric power generation occupies among total power generation is as low as approximately $2 \%$, 
which is far lower than that of thermal or nuclear power generation. However, hydroelectric power generation can instantly supply power during periods where there is a sudden increase in power usage, as it requires only a short period of time for power generation. Moreover, it has the advantage of being an eco-friendly energy resource. Thanks to these advantages, hydroelectric power generation has an important position in energy production despite its making up only a small proportion of overall power generation.

Many studies on the efficient operation of reservoirs have been actively pursued. Examining the research regarding dam operation optimization, Lee et al. [2] developed a model that maximizes hydroelectric power generation for the long-term operation of the Daecheong multipurpose dam using sequential linear programming (SLP) and compared it with dynamic programming (DP). Baliarsingh and Kumar [3] examined an optimal operation method for a multipurpose dam in the Mahanadi River basin in India using stochastic linear programming, which can consider the uncertainty of water resources. Kim and Park [4] investigated the economic operation of hydroelectric power generation using a sample of two multipurpose dams and five hydroelectric dams in the Han River water system. For the purpose of satisfying water demand, the study analyzed the dams using mixed integer programming (MILP) and compared the analysis results with the actual operation. Yi [5] developed a combined mixed integer programming with a sample from the lower Colorado River basin and conducted a comparison analysis with the existing operation method. Lee et al. [6] suggested sampling stochastic linear planning (SSLP) based on stochastic methodology for the purpose of building a plan for an optimal multi-reservoir conjunctive operation. Ge et al. [7] suggested an optimal operation method for short-term hydroelectric power generation that considers water time delay by using mixed integer linear programming.

The studies conducted so far mainly used an optimization model such as LP, NLP, and DP to develop a method to achieve efficient water supply or to optimize power generation. This study developed an LP model that can optimize the power generation of eight dams in the Han River basin in Korea. As a dam's power generation fluctuates greatly according to the inflow, an optimal model is not easy to estimate. In this study, a power generation optimization model was developed for eight dams in the Han River basin through modification of the constraint and objective functions of the LP model, which results were compared with historical data of power generation over the past ten years (2004-2013).

\section{Theoretical background}

\subsection{Linear programming}

Linear programming is a mathematical method that finds the optimal solution of a linear function under constraint where the objective function and constraint should be expressed in first-order. As the linear programming has a clearly defined model and advanced solution methods, it can solve relatively high dimensional problems. Although the linear programming cannot take into account the correlation or 
interdependence among the variables, it is receiving a lot of attention as a model building tool since it can suggest an optimal alternative in a complicated decision making problem. Even in a case where some objective functions or constraints contain a nonlinear equation, the equation is soluble after linearizing the equation using methods such as successive linear programming (SLP), piecewise linearization (PL), and Taylor expansion.

\subsection{Taylor expansion}

Taylor expansion means expressing differentiable functions at one point in polynomial forms. It can make solving the problem much easier as it converts the complex high order function into a sum of simple polynomial functions. In Taylor series, the higher the order is, the closer the approximation can be. However, the first-order or second-order is used as the degree of Taylor series in general. When we approximate $\mathrm{f}(\mathrm{x})$ in second-order polynomial using Taylor expansion, it can be expressed as in Equation (1) below.

$$
\mathrm{f}(\mathrm{x})=\mathrm{f}^{\prime}(\mathrm{a})+\mathrm{f}^{\prime}(\mathrm{a})(\mathrm{x}-\mathrm{a})+\frac{f^{\prime \prime}(a)}{2}(x-a)^{2}+Q(x)
$$

where, $a$ is non zero, and it represents an infinitely differentiable constant in the case of the function $f(x)$ is $x=a \cdot Q(x)$ includes the rest terms other than the second-order polynomial. In this study, the term was not considered as we determined that it has only a minor impact on the equation.

\section{Application of the model}

\subsection{Introduction of the Han River basin}

The Han River basin is located in the middle part of the Korean peninsula covering the latitude $36^{\circ} 30^{\prime}-38^{\circ} 55^{\prime}$ and longitude $126^{\circ} 24^{\prime}-129^{\circ} 02^{\prime}$. It has a total river area of $25,953.6 \mathrm{~km}^{2}\left(35,770.46 \mathrm{~km}^{2}\right.$ including North Korea) and a total river extension of $494.44 \mathrm{~km}$. The Han River, the largest river in the middle part of Korea, runs through Seoul, and it is largely divided into the South Han River and the North Han River. The Han River basin contains a total of ten dams, including three multipurpose dams (Soyanggang Dam, Chungju Dam, and Hwengseung Dam), six hydroelectric power generation dams (Goesan Dam, Hwacheon Dam, Chuncheon Dam, Uiam Dam, Cheongpyeong Dam, and Paldang Dam), and one for flood control (Peace Dam). Among them, the Peace Dam was built with the purpose of preparing for the discharge of the Imnan Dam located upstream in North Korea, which does not run at ordinary times. In this study, among the total ten dams, eight dams with a relatively large scale, including the Soyanggang Dam, Chungju Dam, Hwengseung Dam, Hwacheon Dam, Chuncheon Dam, Uiam Dam, Cheongpyeong Dam, and Paldang Dam were used for the model. Data about the dams used in this study and a mimetic diagram are presented in Table 1 and Fig. 1, respectively. 
Table 1: Data on the dams.

\begin{tabular}{|l|c|c|c|c|}
\hline & $\begin{array}{c}\text { Basin area } \\
\left(\mathbf{k m}^{\mathbf{2}}\right)\end{array}$ & $\begin{array}{c}\text { Conservation } \\
\text { Storage } \\
\left(\times \mathbf{1 0}^{\mathbf{6}} \mathbf{m}^{\mathbf{3}}\right)\end{array}$ & $\begin{array}{c}\text { Mean } \\
\text { Annual Inflow } \\
\left(\mathbf{m}^{\mathbf{3}} \mathbf{s e c}\right)\end{array}$ & $\begin{array}{c}\text { Hydropower } \\
\text { Generation } \\
\text { Capacity } \mathbf{( K w})\end{array}$ \\
\hline Hwacheon & 3,901 & 658 & 75.3 & 27,000 \\
\hline Chuncheon & 4,736 & 61 & 98.3 & 28,800 \\
\hline Soyanggang & 2,703 & 1,900 & 55.5 & 200,000 \\
\hline Uiam & 7,709 & 57.5 & 174.1 & 22,500 \\
\hline Cheongpyeong & 9,921 & 82.6 & 225.2 & $\# 1,2: 19,800$ \\
\hline Chungju & 6,648 & 1,789 & 154.5 & 412,000 \\
\hline Hwengseung & 209 & 73.4 & 5.13 & 13,000 \\
\hline Paldang & 23,800 & 18 & 553.4 & 30,001 \\
\hline
\end{tabular}

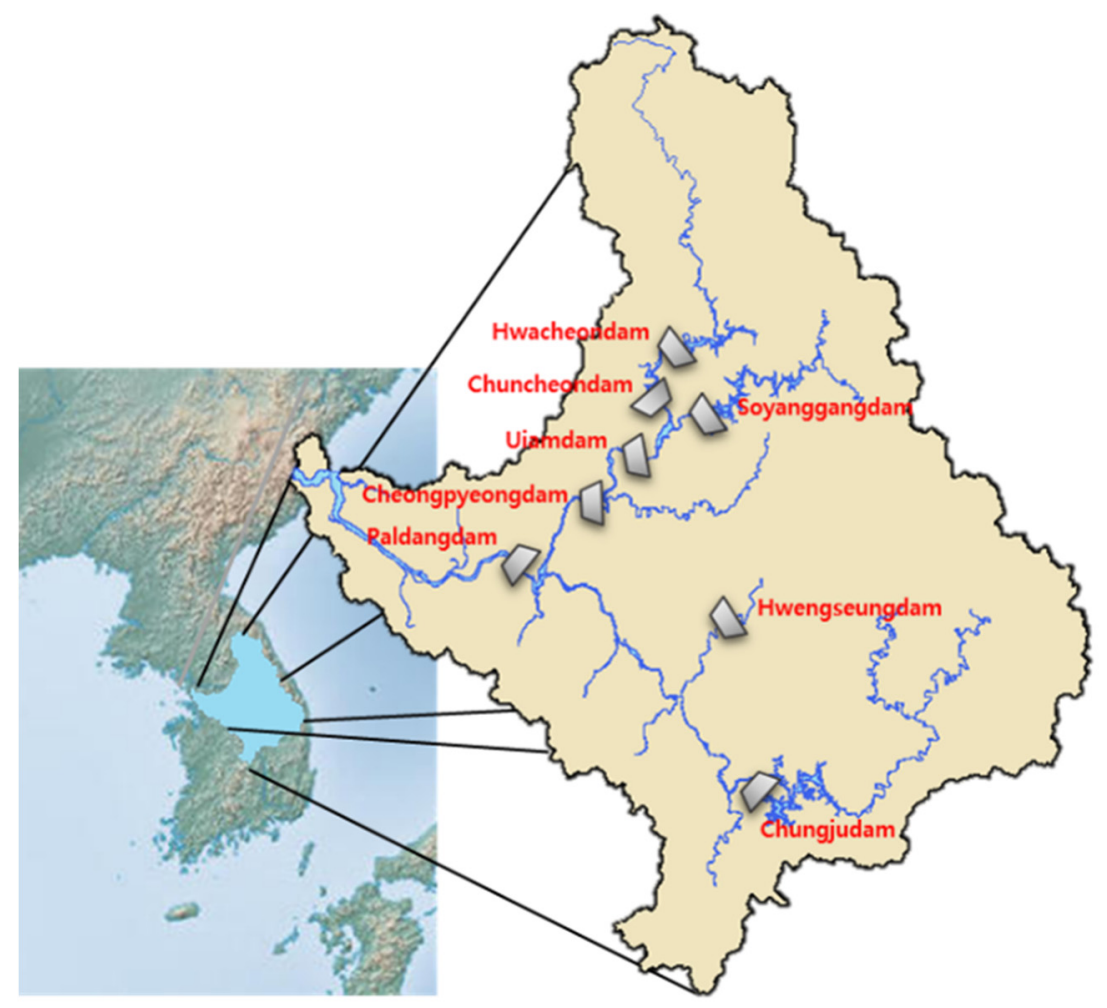

Figure 1: Basin map of Han River water system. 


\subsection{LP model composition}

\subsubsection{Power generation}

Hydroelectric power is generated as the potential energy of water is converted into mechanical energy, which is again converted into electric energy. The power generation produced in the generator can be expressed in a formula as in Equation (2).

$$
P_{t}=9.8 \times \varepsilon_{t} \times \gamma_{t} \times\left(h_{t}-T_{t}-l_{t}\right)
$$

here, $\varepsilon_{t}$ means overall efficiency of the power plant [\%], $\gamma_{t}$ is the monthly average power flow $\left(\mathrm{m}^{3} / \mathrm{sec}\right), h_{t}$ is upstream water level (EL.m), $T_{t}$ is spillway water level (EL.m), and $l_{t}$ is energy loss of head (m).

\subsubsection{Objective function}

In this study, the objective function is to maximize the annual minimum power generation, which can be expressed in a formula as in Equation (3).

$\max E$

where, $E$ means monthly generation (Mwhr).

\subsubsection{Constraint}

As for the constraints of the reservoir model that maximize the monthly generation, hydrologic equation, constraint on monthly reservoir water level, minimum power generation production condition, closing water level, and non-negative condition were taken into account. The power generation estimation condition in nonlinear form was linearized using Taylor expansion. The model's constraints are expressed in equations (4)-(8).

$$
\begin{gathered}
S_{t}=S_{t-1}+i_{t}-x_{t}-w_{t} \\
S_{t} \leq C_{t} \\
S_{t} \geq K_{t} \\
S_{t} \geq S_{1} \\
E-\left(\ln \mathrm{x}_{t}^{0}+\frac{x_{t}}{\mathrm{x}_{t}^{0}}-1\right)-\left(\ln S_{t}^{0}+\frac{S_{t}}{S_{t}^{0}}-1\right) \leq \ln \alpha+\ln \mathrm{c}+\ln \Delta \mathrm{t}
\end{gathered}
$$

where, $S_{t}$ is storage in month $\mathrm{t}\left(10^{6} \mathrm{~m}^{3},\right) i_{t}$ is inflow in month $\mathrm{t}\left(10^{6} \mathrm{~m}^{3}\right), x_{t}$ is generation discharge in month $\mathrm{t}\left(10^{6} \mathrm{~m}^{3},\right), w_{t}$ is gate discharge in month $\mathrm{t}$ $\left(10^{6} \mathrm{~m}^{3},\right), C_{t}$ is storage at normal pool level (EL.m) during January-May and October-December and storage at restricted water level during the flood season of June-September $\left(10^{6} \mathrm{~m}^{3}\right), K_{t}$ is low water level storage in month $\mathrm{t}\left(10^{6} \mathrm{~m}^{3}\right), \mathrm{x}_{t}^{0}$ is monthly average generation discharge $\left(10^{6} \mathrm{~m}^{3}\right)$, and $S_{t}^{0}$ is monthly average 
storage $\left(10^{6} \mathrm{~m}^{3}\right) . \alpha$ is a product of generator efficiency, acceleration of gravity, unit scale factor, etc., which takes a constant value of $2.73 \times 10^{-3}$.

\subsection{Input data}

In this study, the inflow data of eight dams located in the Han River were used for monthly operation. As for the four dams (Hwacheon Dam, Soyanggang Dam, Chungju Dam, and Hwengseung Dam) located upstream that are not affected by discharge from other dams, observed inflow data were used. As for the remainder of the dams, tributary inflow was first computed by subtracting upstream dam discharge in the relevant month from the observed inflow data. Next, the generation discharge, which was obtained from an optimal operation in upstream dams, was added to the spillway discharge to be used as inflow data. Through this computation, we made it possible for the operation result of the upstream dams to have an influence on the downstream dams.

\section{Operation results}

According to the optimal operation results from 2004 to 2013 using observed inflow data and the LP model, power generation was improved $37 \%$ compared to the historical operation data, while no spillway draft was observed. Among the eight dams, the operation results of the Hwengseung Dam are presented in Figs 2 and 3 using box plot.

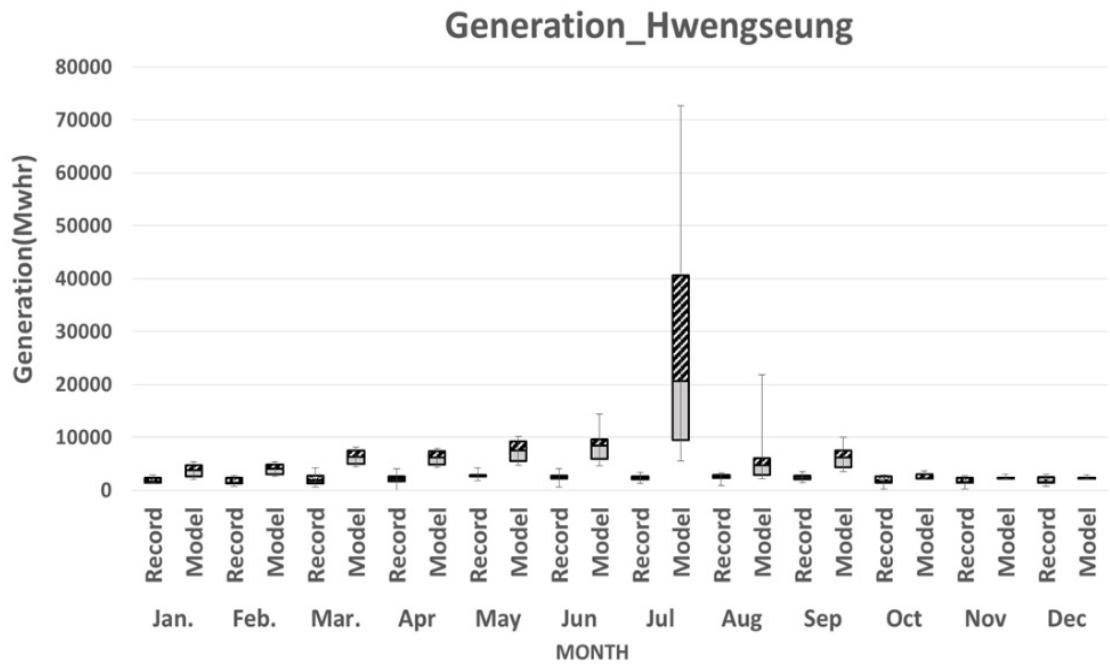

Figure 2: Power generation at the Hwengseung Dam. 


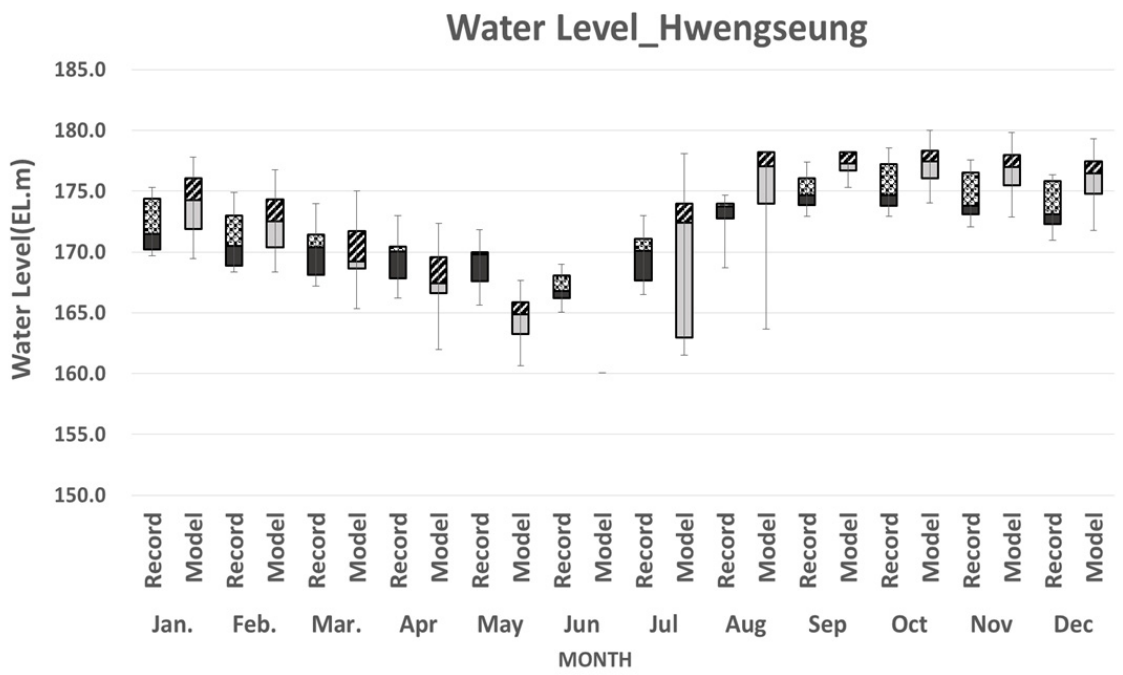

Figure 3: Water level at the Hwengseung Dam.

In Figs 2 and 3, Historical and Model mean historical value and the optimized model value, respectively, of the Hwengseung Dam's power generation and water level. As is shown in Fig. 2, the model's power generation was higher in every month. In Korea, 90\% of the annual precipitation occurs between June and September. Hence, it is important to prepare for the potential damage from floods during this period. In the actual operations, spillway discharge occurred often in order to prevent dam collapse resulting from floods. In contrast, in the model, there was no spillway discharge, as it followed monthly operation and the generation discharge was enough to satisfy the constraint. Comparing the water level data presented in Fig. 3, during the period of June-September that has the flood risk, the model results showed lower water levels than the historical data, while it showed higher water levels in the dry season. This implies that the model would produce a relatively easier water supply in case of an emergency. Among the remaining seven dams, some showed inconsistent results, but overall, the results were similar. Table 2 presents the annual average of hydropower generation and the monthly water level data of all dams that were used as the subject of this research.

The comparison of average power generation shown in Table 2 indicates that the model's power generation is larger than historical data in all dams. As was previously mentioned, this result can be attributed to the fact that spillway draft during the flood season disappeared, resulting in increased power generation. Nevertheless, the model also showed relatively high power generation in other periods. 
Table 2: Comparison between historical data and operation model results.

\begin{tabular}{|l|c|c|c|c|c|c|}
\hline & \multicolumn{2}{|c|}{$\begin{array}{c}\text { Mean annual } \\
\text { hydropower generation } \\
\text { (Mwhr) }\end{array}$} & $\begin{array}{c}\text { Mean annual } \\
\text { water level_drought } \\
\text { season (Jun.-Sep.) } \\
\text { (EL.m) }\end{array}$ & $\begin{array}{c}\text { Mean annual } \\
\text { water level_flood } \\
\text { season (Jan.-May, } \\
\text { Oct.-Dec.) } \\
\text { (EL.m) }\end{array}$ \\
\hline Historical & Model & Historical & Model & Historical & Model \\
\hline Hwacheon & $17,950.1$ & $24,456.2$ & 149.11 & 151.62 & 167.76 & 170.30 \\
\hline Chuncheon & $10,906.1$ & $14,754.6$ & 90.98 & 90.92 & 101.61 & 99.71 \\
\hline Soyanggang & $44,363.3$ & $50,813.6$ & 154.92 & 155.36 & 174.46 & 177.23 \\
\hline Uiam & $12,445.9$ & $14,706.8$ & 63.11 & 62.82 & 70.31 & 68.33 \\
\hline Cheongpyeong & $22,834.3$ & 28408.1 & 152.83 & 153.09 & 171.13 & 170.56 \\
\hline Chungju & $67,752.9$ & $78,517.1$ & 115.24 & 117.26 & 129.51 & 130.32 \\
\hline Hwengseung & $2,123.5$ & $6,915.4$ & 152.83 & 153.09 & 171.13 & 170.56 \\
\hline Paldang & $35,467.4$ & $74,428.6$ & 22.37 & 22.47 & 25.09 & 25.05 \\
\hline & & & & & & \\
\hline
\end{tabular}

Generally speaking, it is ideal to keep a dam's water level high during the dry season for a stable water supply, while keeping it at low levels during the flood season in order to prepare for damage from floods. By using the model developed in this study, the water level could be kept at a level that is higher than or similar to that in the historical model during the dry season. During the flood season, all dams except for two dams showed similar or lower water levels in our model. In summary, the model developed in this study improved power generation, while keeping the irrigation stability and flood control stability similar to or better than that represented in the historical data, both during the dry season and the flood season.

\section{Conclusion}

This paper used an LP model to optimize the power generation of eight dams in the Han River water system located in the middle region of Korea. Monthly operation was carried out using observed inflow data during a total period of ten years from 2004 to 2013, and Taylor expansion was used to linearize the computation equation. For the verification of the model, the resulting values were compared with historical data about the generation and water levels of each dam.

According to the comparison results, the model developed in this study could maintain relatively high water levels during the dry season, while maintaining low levels during the flood season, satisfying the need for both flood control stability and irrigation stability. The total power generation improved $37 \%$ using the model. The largest reason behind such results is that all of the spillway discharge that occurred in the historical operations was operated as generation discharge in the optimal model. Moreover, it is a deterministic model where the historical inflow 
data over the past ten years were already known. However, the results are still significant as it showed relatively large power generation even when excluding the flood season.

The optimal operation model developed in this study can be helpful to dam operators in building generation plans in the future. It also enables a flexible response when inflow occurs during actual operation that is different from the initial planning expectations, as it can generate new operational alternatives appropriate for the changing situation. Further studies aimed at increasing the prediction accuracy of inflow could be combined with these study results to contribute to the efficient usage of water resources, enhancement of flood control stability, and increases in power generation.

\section{Acknowledgement}

This work was supported by a National Research Foundation of Korea (NRF) grant funded by the Korean government (MEST) (No 2013-065006).

\section{References}

[1] Stocker, T.F., D. Qin, G.-K. Plattner, M. Tignor, S. K. Allen, J. Boschung, A. Nauels, Y. Xia, V. Bex and P.M. Midgley (eds.), IPCC, 2013: Summary for Policymakers, Climate Change 2013: The Physical Science Basis. Contribution of Working Group I to the Fifth Assessment Report of the Intergovernmental Panel on Climate Change, Cambridge University Press, Cambridge, United Kingdom and New York, NY, USA, 2013.

[2] Lee, K. T., Kwon, O.H. \& Ko, S.K., Maximization of Hydro-power Generation by Successive Linear Programming Technique. Korean Society of Civil Engineers, 15(5), pp. 1343-1349, 1995.

[3] Baliarsingh, F. \& Kumar, D. N., Stochastic Linear Programming for Optimal Reservoir Operation: A Case Study, Proc. of International Conference on Large Scale Water Resources Development in Developing Countries: New Dimensions of Prospects and Problems, Kathmandu, Nepal, pp. 124-130, 1997.

[4] Kim, S. K. \& Park, Y. J., Mixed Integer Programming for the optimal multioperation of the reservoir, Proc. the Annual Conference of Korean Institute of Industrial Engineers, pp. 152-161, 1998.

[5] Yi, J. E., Optimal Unit Commitment of Hydropower System Using Combined Mixed Integer Programming. Journal of Korean Water Resources Association, 32(5), pp. 525-535, 1999.

[6] Lee, Y. D., Kim, S. K. \& Kim, J. H., A Sampling Stochastic Linear Programming Model for Coordinated Multi-Reservoir Operation, Proc. The Annual Conference of Korean Institute of Industrial Engineers, S, pp. 672675, 2004.

[7] Ge, X. I., Zhang, L. z., Shu, J. \& Xu, N. f., short-term hydropower optimal scheduling considering the optimization of water time delay, Electric Power Systems Research 110, pp. 188-197, 2014. 